\title{
Article \\ Cell-Extrinsic Differentiation Block Mediated by EphA3 in Pre-Leukaemic Thymus Contributes to Disease Progression
}

\author{
Adriana C. Pliego Zamora ${ }^{1}\left(\mathbb{D}\right.$, , Hansini Ranasinghe ${ }^{1}$, Jessica E. Lisle ${ }^{1}$, Chun $\mathrm{Ki} \mathrm{Ng}^{1}$, Stephen Huang ${ }^{1}$, \\ Racheal Wadlow ${ }^{1}$, Andrew M. Scott ${ }^{2,3}$, Andrew W. Boyd ${ }^{4}$ and Christopher I. Slape ${ }^{1, *(D)}$
}

1 The University of Queensland Diamantina Institute, The University of Queensland, Brisbane 4102, Australia; a.pliegozamora@uq.edu.au (A.C.P.Z.); hansini.ranasinghe@uq.net.au (H.R.); j.lisle@uq.edu.au (J.E.L.); chun.ng@uq.edu.au (C.K.N.); s.huang@uq.edu.au (S.H.); r.wadlow@uq.edu.au (R.W.)

2 Olivia Newton-John Cancer Research Institute and La Trobe University, Heidelberg 3084, Australia; andrew.scott@onjcri.org.au

3 Faculty of Medicine, University of Melbourne, Melbourne 3000, Australia

4 Department of Medicine, The University of Queensland, Brisbane 4072, Australia; aw.boyd@uq.edu.au

* Correspondence: c.slape@uq.edu.au

check for updates

Citation: Pliego Zamora, A.C.; Ranasinghe, H.; Lisle, J.E.; Ng, C.K.; Huang, S.; Wadlow, R.; Scott, A.M.; Boyd, A.W.; Slape, C.I. Cell-Extrinsic Differentiation Block Mediated by EphA3 in Pre-Leukaemic Thymus Contributes to Disease Progression. Cancers 2021, 13, 3858. https:// doi.org/10.3390/cancers13153858

Academic Editor: Francesco Bertolini

Received: 31 May 2021

Accepted: 27 July 2021

Published: 31 July 2021

Publisher's Note: MDPI stays neutral with regard to jurisdictional claims in published maps and institutional affiliations.

Copyright: (C) 2021 by the authors Licensee MDPI, Basel, Switzerland. This article is an open access article distributed under the terms and conditions of the Creative Commons Attribution (CC BY) license (https:/ / creativecommons.org/licenses/by/ $4.0 /)$.
Simple Summary: The NUP98-HOXD13 (NHD13) mouse is a model of T-cell leukaemia (T-ALL) featuring a pre-leukemic phase, in which T-cell progenitors from the thymus of an NHD13 mouse can engraft into the thymus of a recipient mouse-an ability that normal T-cell progenitors do not possess. However, loss of this engraftment ability (by deletion of the Lyl1 gene) did not result in any loss of leukemogenesis activity, indicating the activity of redundant oncogenic pathways in this model. Having observed an overexpression of the EphA3 protein in the NHD13 thymocytes, we hypothesized that this gene might be involved in a redundant leukaemogenic pathway. Deletion of EphA3 did not affect the engraftment ability of the thymocytes, but did reduce the incidence of T-ALL. We thus uncovered a distinct mechanism of leukaemogenesis, which we believe operates in parallel to that mediated by Lyl1.

Abstract: We recently characterised the NUP98-HOXD13 (NHD13) mouse as a model of T-cell preleukaemia, featuring thymocytes that can engraft in recipient animals and progress to T-cell acute lymphoblastic leukaemia (T-ALL). However, loss of this engraftment ability by deletion of Lyl1 did not result in any loss of leukemogenesis activity. In the present study, we observe that NHD13 thymocytes overexpress EPHA3, and we characterise thymocyte behaviour in NHD13 mice with deletion of EphA3, which show a markedly reduced incidence of T-ALL. Deletion of EphA3 from the NHD13 mice does not prevent the abnormal accumulation or transplantation ability of these thymocytes. However, upon transplantation, these cells are unable to block the normal progression of recipient wild type (WT) progenitor cells through the normal developmental pathway. This is in contrast to the $E p h A 3^{+/+}$NHD13 thymocytes, which block the progression of incoming WT progenitors past the DN1 stage. Therefore, EphA3 is not critical for classical self-renewal, but is essential for mediating an interaction between the abnormally self-renewing cells and healthy progenitors-an interaction that results in a failure of the healthy cells to differentiate normally. We speculate that this may orchestrate a loss of healthy cell competition, which in itself has been demonstrated to be oncogenic, and that this may explain the decrease in T-ALL incidence in the absence of EphA3. We suggest that pre-leukaemic self-renewal in this model is a complex interplay of cell-intrinsic and -extrinsic factors, and that multiple redundant pathways to leukaemogenesis are active.

Keywords: T-ALL; Eph; pre-leukaemia; cell competition

\section{Introduction}

T-cell acute lymphoblastic leukaemia (T-ALL) is a clonal malignancy caused by the accumulation of genomic lesions that disrupt the development of T cells [1-4]. T-ALL does 
not present clinically until it is in its acute phase, but there is evidence from both murine models and humans that a pre-malignant phase exists [5-7]. Understanding the drivers of this pre-malignant phase, and the drivers of subsequent transformation to acute phase disease, may identify new modes of clinical surveillance and therapy.

The NUP98-HOXD13 (NHD13) transgenic mouse is a model of HoxA-driven T-ALL, with pre-leukaemic thymocytes that exhibit abnormal behaviour prior to the development of overt T-ALL. NHD13 thymocytes accumulate abnormally in the DN2 differentiation stage, and are capable of engraftment upon transplantation. After a latency period, the mice develop T-ALL $[6,8,9]$. NHD13 thymocytes require the Lyl1 gene for their engraftment ability, but although NHD13 Lyl1 knockout (NHD13-Lyl1KO) thymocytes cannot engraft, NHD13-Lyl1KO mice still succumb to T-ALL at the same rate [6]. Therefore, it appears that the abnormal self-renewal ability of NHD13 thymocytes-for which engraftment is regarded as a proxy - is not required for the induction of T-ALL. This stands in contrast to the Lck-LMO2 transgenic mouse model of LMO-driven T-ALL, in which abnormal self-renewal of thymocytes is also dependent on Lyl1, but deletion of Lyl1 prevents the formation of T-ALL [7]. This suggests a redundancy of the oncogenic mechanisms in the NHD13 mice that may be specific to the HoxA-driven T-ALLs, and led us to investigate what other mechanisms may be occurring.

We noted abnormal expression of EPHA3 in the expanded DN2 population of NHD13 thymocytes. EphA3 is a member of the Eph family of cell-surface receptor tyrosine kinases which, with their ephrin ligands, can modulate cell adhesive properties as well as coordinate cell movement, and play critical roles in development, tissue homeostasis, and cancer [10-14]. Importantly, EphA2 (which is closely related to EphA3) is important for tumour-suppressive cell competition in epithelial sheets [15]. Our focus-EphA3-is overexpressed in different types of human leukaemia, including T-ALL [16-19]. There is evidence implicating EphA3 in regulating stem-like features in leukaemic stem cells (LSCs) [20] and solid cancer stem cells (CSCs) [21,22]. EPHA3 is a promising therapeutic target in cancer [23], including in glioblastoma [24,25]. Moreover, EPHA3 is a viable anti-leukaemic target, with the success of an activating monoclonal antibody (IIIA4), targeted payload delivery, or RNAi-mediated EPHA3 knockdown in models of multiple myeloma [26] and pre-B-ALL [27], as well as in human myeloid malignancies [28]. We hypothesized that EphA3 might be involved in a parallel oncogenic pathway, and investigated its involvement in the NHD13 T-ALL disease.

\section{Materials and Methods}

\subsection{Mouse Strains}

Transgenic NHD13 mice [9] and EphA3 germline knockout (EphA3KO) mice [29] have been previously described. The double-transgenic NHD13-EphA3 ${ }^{-1-}$ mouse was generated by crossing NHD13 and EphA3KO mice. All strains were back-crossed at least 12 generations onto a C57BL/ 6 background. CD45.1 WT mice were purchased from ARC, Perth, Australia. Mice were euthanised at 6 or 12 weeks of age accordingly, using $\mathrm{CO}_{2}$, and then thymuses were dissected. Animal experiments were approved by the Animal Ethics Committee of the University of Queensland.

\subsection{Tissue Processing}

Single-cell thymocyte suspensions were obtained by gently pressing the thymus onto a $40-\mu \mathrm{m}$ cell strainer (BD Falcon, Franklin Lakes, NJ, USA) with a syringe plunger and rinsing with PBS supplemented with $2 \%$ FBS ( $2 \%$ FBS-PBS). Cell counts and cell viability were determined using Trypan blue. Thymocyte samples were used for flow cytometry analysis, transplantation experiments, or stored in TRIzol (Invitrogen, Waltham, MA, USA) at $-80^{\circ} \mathrm{C}$. 


\subsection{Flow Cytometry: Thymocyte DN Populations, Chimerism, and Cell Cycle}

For each mouse, $1 \times 10^{6}$ thymocytes were blocked with anti-CD16/32 (FcR receptor) and stained with Zombie Aqua, lineage (B220, TER119, GR-1, MAC-1), CD4, CD8, CD44, CD25, C-KIT, and EPHA3. Double-negative (DN) populations were determined as lineage-, $\mathrm{CD} 44^{-}, \mathrm{CD}^{-}, \mathrm{CD}_{4} 4^{-/+}, \mathrm{CD} 25^{-/+}$, and C-KIT ${ }^{-/+}$. The expression of EphA3 was evaluated in populations DN 1-4. In addition to the DN panel, CD45.1 and CD45.2 were included for chimerism studies. For cell cycle studies, cells were stained as previously described for extracellular markers, then fixed and permeabilized with Fix \& Perm Cell Permeabilization reagents (Thermo Fisher, Waltham, MA, USA), stained first with Ki67, and then with $20 \mu \mathrm{M}$ Hoechst 33342 (Sigma-Aldrich/Merck, Burlington, VT, USA), in a solution with $0.05 \%$ saponin (Sigma-Aldrich/Merck) and $1 \mu \mathrm{g} / \mathrm{mL}$ RNase A (Sigma-Aldrich/Merck) [30]. Cells were analysed by flow cytometry using a BD LSR FortessaX-20. Data were analysed using FlowJo 10.

\subsection{Thymocyte Transplantation}

Six-week-old donors (CD45.2) of each indicated genotype were euthanised using $\mathrm{CO}_{2}$ and their thymuses were dissected. Single thymocyte suspensions were obtained as previously described. One-sixth of the thymus in $200 \mu \mathrm{L}$ of PBS was intravenously injected into female mice (CD45.1) sub-lethally irradiated with $6.5 \mathrm{~Gy}$ from a ${ }^{60} \mathrm{C} \gamma$. Four weeks post-transplantation, recipients were euthanised and a serial transplantation was performed as described above, for a total of 4 subsequent times. Samples of thymocytes were stained and analysed for chimerism and cell cycle studies, as previously described.

\subsection{Gene Expression Study}

Total RNA was isolated from thymocytes using TRIzol (Invitrogen) reagent and a GenElute mammalian total RNA miniprep kit (Sigma-Aldrich). Day 17 embryonic RNA was used to validate primers (Clontech/Takara, Kyoto, Japan). cDNA was synthesised with Superscript III (Invitrogen). Primers for HoxA5, HoxA7, HoxA9, HoxA10, Lmo2, Hhex, and Klf2 were designed in-house and purchased from IDT. For all qRT-PCR reactions, PowerU $\mathrm{p}^{\mathrm{TM}}$ SYBR ${ }^{\mathrm{TM}}$ Green Master Mix (Applied Biosystems, Waltham, MA, USA) was used, except for Lyl1, for which TaqMan Fast Advanced Master Mix (Applied Biosystems) was used. Relative expression of target transcripts was analysed using the ViiA 7 Real-Time PCR System (Thermo Fisher Scientific, Waltham, MA, USA). Expression was normalised to two reference genes: Hprt1 and B2m.

\subsection{Disease Progression Study}

Groups of mice were designed to enable detection of a relative hazard of 0.5 with type I and II error rates of 0.3. Mice that reached ethical endpoints were euthanised using $\mathrm{CO}_{2}$ and their thymomas/thymuses were harvested. T-ALL cell profiles were used to corroborate diagnosis. Single thymocyte samples were obtained, stained, and analysed via flow cytometry, as previously described.

\subsection{Statistical Analyses}

GraphPad Prism 7.3. was used for analysis. We used one-way ANOVA with Tukey's post hoc analysis. Survival curve analysis was carried out using the Mantel-Cox test. ${ }^{*} p<0.03,{ }^{* *} p<0.002,{ }^{* * *} p<0.0002$, and ${ }^{* * * *} p<0.0001$. Bars represent the SEM.

\section{Results}

\subsection{EphA3 Is Abnormally Expressed in NHD13 Thymocytes}

We characterised WT and NHD13 thymocytes by flow cytometry (Figure 1A). Consistent with previous studies [6,8], the NHD13 thymuses showed an abnormal accumulation of thymocytes in the DN2A (CD44 $\left.{ }^{\mathrm{hi}}, \mathrm{CD} 25^{+}\right)$stage (Figure 1B). We also observed an abnormally high level of expression of the C-KIT protein in the $\mathrm{CD}^{2} 5^{+}$fraction (Figure 1B), as previously described [6]. We examined the expression of EPHA3 via flow cytometry, 
and found that EPHA3 is specifically expressed in a subset of the expanded DN2A (CD4 ${ }^{-}$, $\mathrm{CD}^{-}, \mathrm{CD}^{+} 4^{+}, \mathrm{CD}^{2} 5^{+}$) population of NHD13 thymocytes (Figure 1C).

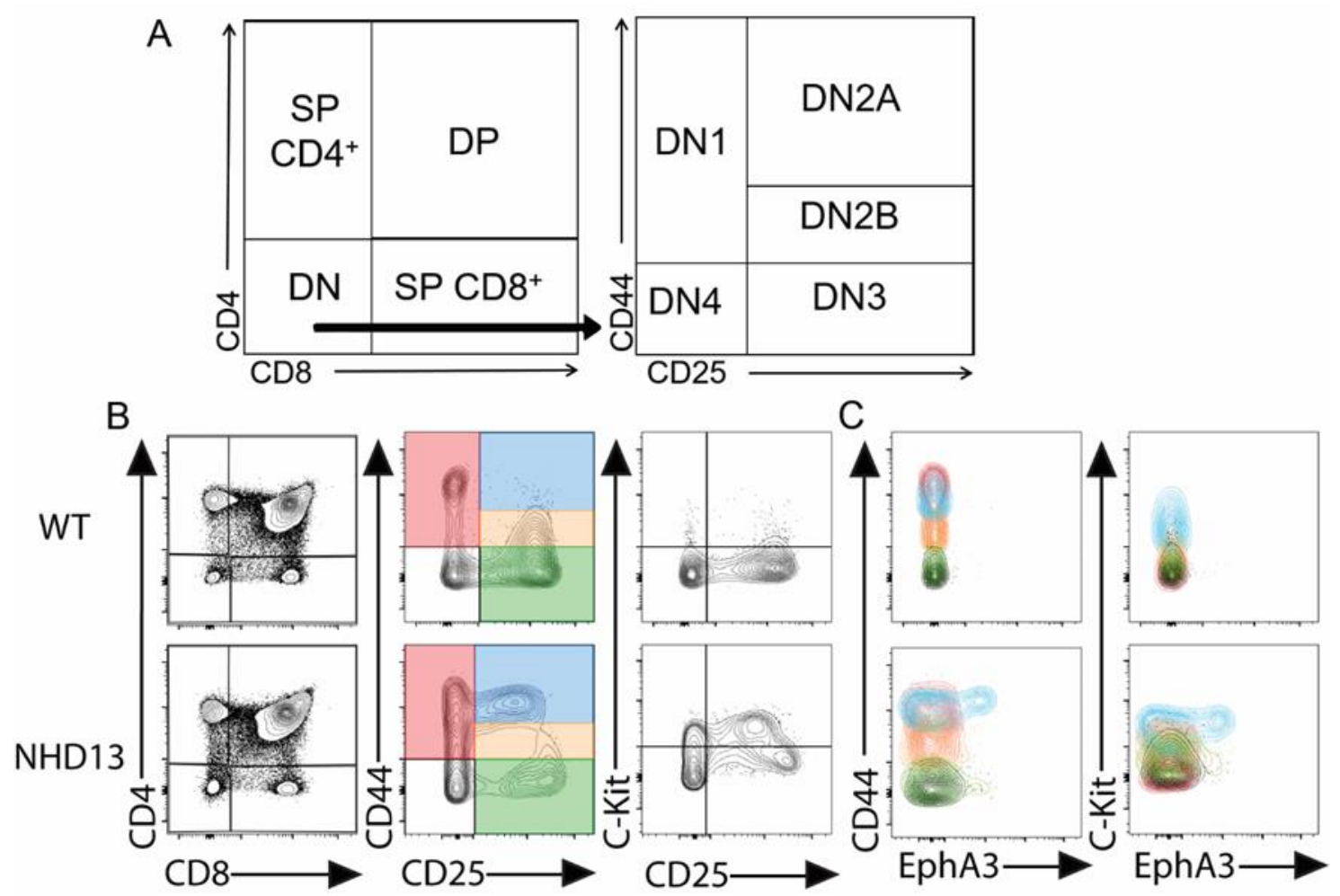

Figure 1. EPHA3 is expressed in DN2A NHD13 thymocytes. (A) Gating strategy to examine thymocytes via flow cytometry. (B) Representative cell profiles using CD4/CD8, CD44/CD25, and C-KIT/CD25. (C) Detection of EPHA3 in DN1-4. The colour of the contours matches the colour of the gated DN1-4 populations from panel B.

\subsection{EphA3 Deletion Delays the NHD13 Thymic Phenotype}

To assess the role of EphA3 in the NHD13 thymus, we crossed the NHD13 transgene onto an EphA3 germline deletion background to generate EphA3-deficient NHD13 mice (NHD13-EphA3 ${ }^{-/}$). We confirmed the absence of EPHA3 in the thymocytes via flow cytometry (Figure 2A). Analysis of the thymuses of each genotype (WT, EphA3 ${ }^{-1-}$, NHD13-

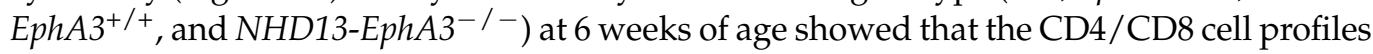
(Figure 2B and Supplementary Figure $\mathrm{S} 1$ ) were similar, and that the overexpression of C-KIT remained high in both NHD13-EphA3 ${ }^{+/+}$and NHD13-EphA3 ${ }^{-/-}$DN2A thymocytes (Figure 2B). However, there were significant differences in the cellularity of the thymus and the proportions of the DN subpopulations (CD44/CD25). The reduced cellularity of the NHD13 thymus was corrected by the deletion of EphA3 (Figure 2D). Furthermore, the accumulation of DN2A cells in the NHD13 thymus was decreased by the deletion of EphA3 (Figure 2B,D). The proportions of the DN1 and DN2B populations in the NHD13-EphA3 ${ }^{-1-}$ thymus were similar to those in the WT and $E p h A 3^{-/-}$control thymuses, correcting the abnormalities seen in the NHD13-EphA3 ${ }^{+/+}$thymus. The proportion of DN2A and DN3 cells was also partially normalised (Figure 2D). The incomplete nature of these corrections, however, suggested that a biological difference between the NHD13-EphA3 ${ }^{-/-}$and the WT and $E p h A 3^{-1-}$ controls remains. 
A

DN

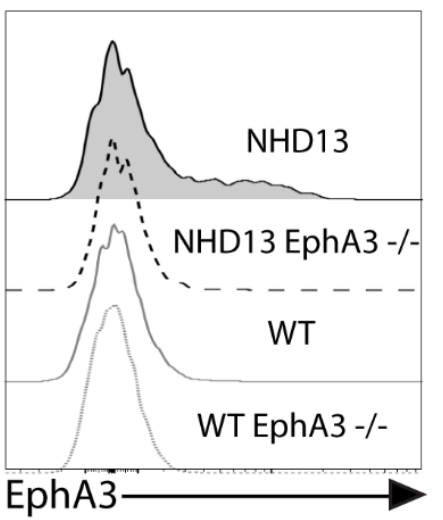

B

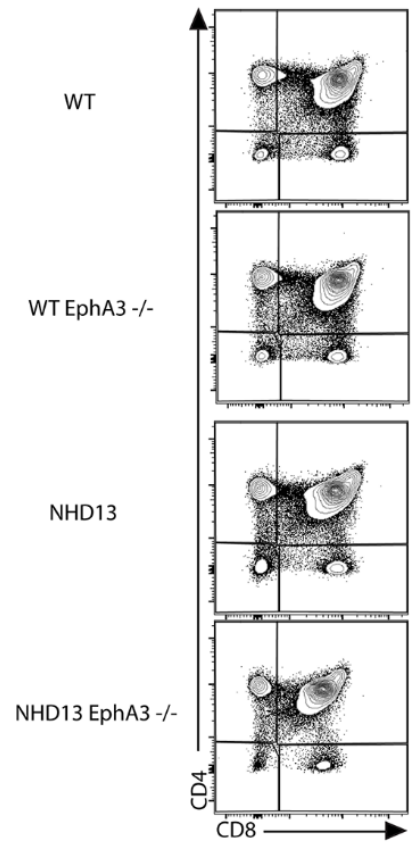

$\mathrm{D}$

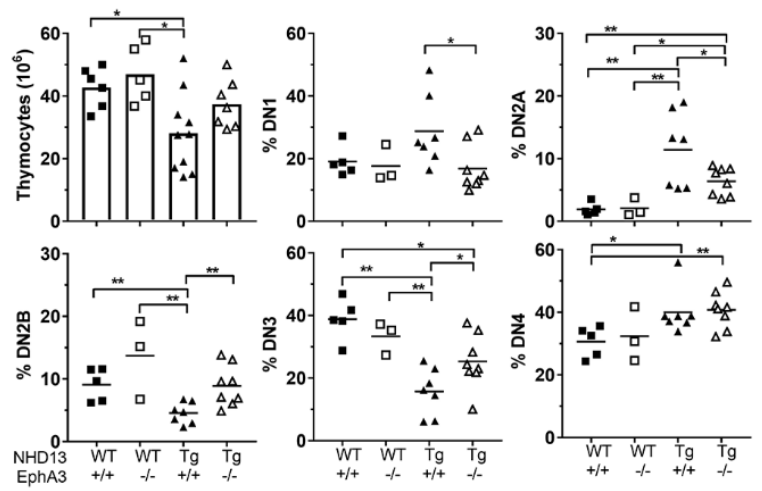

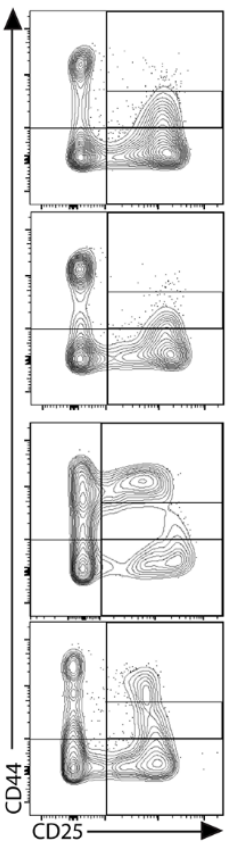

C

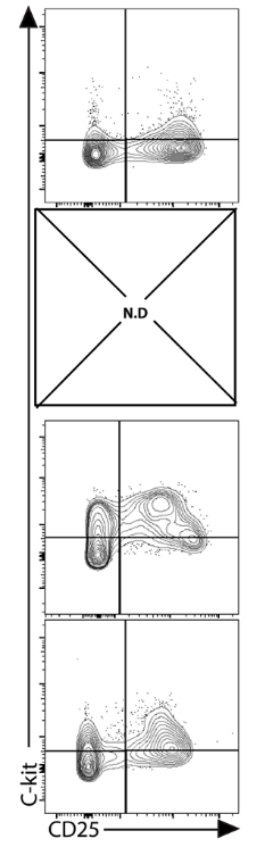

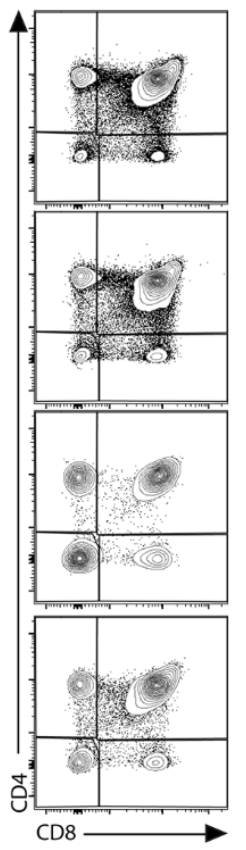

E

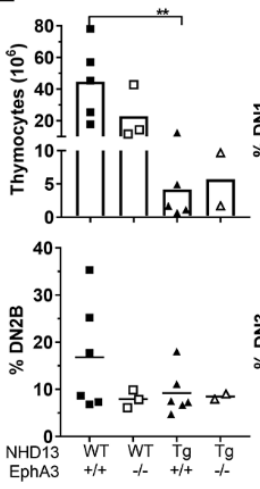

12 week old
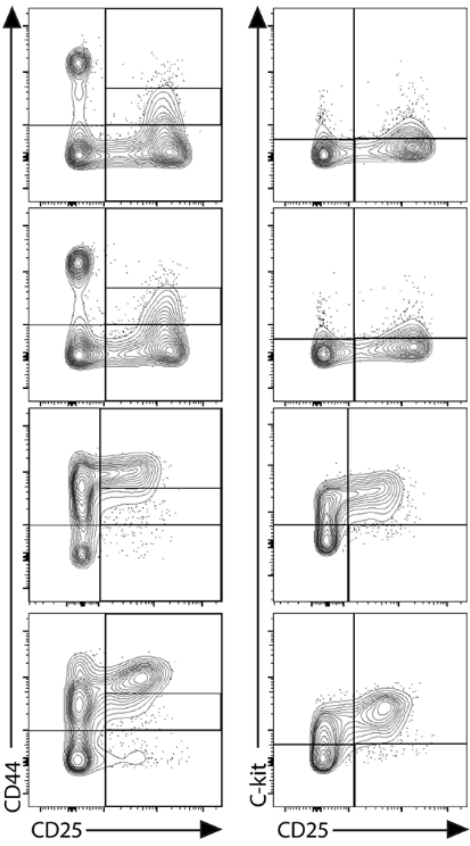

CD25

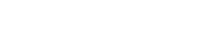

Figure 2. The NHD13 thymocyte differentiation block is transiently rescued by loss of EphA3. (A) Confirmation of EphA3 deletion in DN (CD4 ${ }^{-} / \mathrm{CD}^{-}$) thymocytes by flow cytometry. (B) Representative thymocyte profiles using CD4/CD8, CD44/CD25, and C-KIT/CD25 for each indicated genotype in 6-week-old and (C) 12-week-old mice. (D) Quantitation of thymic cellularity and proportions of DN1, DN2A, DN2B, DN3, and DN4 in 6-week-old and (E) 12-week-old mice. Data represent the mean, while points represent individual mice (3-8 per group). $p$-values were calculated using Student's $t$-test $\left({ }^{*} p<0.05,{ }^{* *} p<0.005,{ }^{* * *} p<0.0005,{ }^{* * * *} p<0.00005\right)$. N.D.: not done. 
To gain further insight, we characterised a cohort of older mice. At 12 weeks of age, the loss of EphA3 did not alter the phenotype of NHD13 thymuses, as shown by the similarity in CD4/CD8 cell profiles (Figure 2C), with significantly increased DN, SP4, and SP8 populations as well as decreased DP populations (Supplementary Figure S1) in both the $\mathrm{NHD13}-\mathrm{EphA3}^{+/+}$and NHD13-EphA3${ }^{-/-}$thymuses. Moreover, the low cellularity (Figure 2E), accumulation of DN2A thymocytes (Figure 2C,E), and increased DN1 and decreased DN3 proportions (Figure 2E) were the same in both $N H D 13-E p h A 3^{+/+}$and NHD13-EphA3 ${ }^{-/-}$thymuses. Therefore, phenotypes that were rescued or partially rescued at 6 weeks of age were once again abnormal at 12 weeks of age.

In the thymus of WT mice, the loss of EphA3 had no effect at either timepoint, exhibiting no significant changes in the thymus cellularity (Figure 2D,E), equal proportions of DN, DP, SP4, SP8 (Supplementary Figure S1), and DN1-4 (Figure 2D,E) populations, and equal cell profiles (Figure 2B,C) in both WT and $E p h A 3^{-/-}$.

Taken together, these results suggest that the deletion of EphA3 delays, but does not prevent, the NHD13 thymus phenotype.

\subsection{EphA3 Deletion Reduces T-ALL Incidence in NHD13 Mice}

To directly determine the impact of the absence of EphA3 on T-ALL occurrence in this model, we compared the T-ALL-free survival of NHD13-EphA3 $3^{++}$and NHD13-EphA3 ${ }^{-/-}$ mice (Figure 3A). Both wild-type $(n=13)$ and $\mathrm{EphA3}^{-/-}(n=17)$ cohorts survived without the development of any T-ALL. T-ALL occurred in the NHD13-EphA3 ${ }^{-1-}$ mice at a lower frequency than in the NHD13- EphA3 $3^{+/+}$mice $\left(9 / 30(30 \%) \mathrm{NHD13}^{-E p h A 3^{+/+}}\right.$mice developed T-ALL, as opposed to $4 / 25$ (16\%) NHD13-EphA3 ${ }^{-/-}$mice). The T-ALL-free survival curves obtained with the Mantel-Cox test were significantly different $(p=0.0418)$. The curves overlap early in the disease course and then deviate late, perhaps suggesting that EphA3 is especially important in late-onset T-ALL in this model. It is important to note that NHD13 mice also develop acute myeloid leukaemia (AML), separate from the development of T-ALL in the thymus ${ }^{6}$. There was no difference between NHD13-EphA3 ${ }^{-/-}$mice and $\mathrm{NHD13}-\mathrm{EphA3}^{+/+}$mice in the incidence of AML in this cohort (Supplementary Figure S2), and AML events were censored from the T-ALL-free survival curve. The only difference seen between NHD13-EphA3 ${ }^{-/-}$and NHD13- $E p h A 3^{+/+}$survival was due to the reduced incidence of T-ALL.

We compared the immunophenotypes of several T-ALLs arising from NHD13-EphA3 $3^{+/+}$ or NHD13-EphA3 ${ }^{-/-}$mice (Figure 3B,C). No differences were noted in the CD4/CD8 profiles between groups, as they vary considerably from sample to sample, independently of the presence of EphA3. The DN (CD44/CD25) profiles from the NHD13-EphA3 ${ }^{+/+}$mice show an accumulation of thymocytes in the DN1 (4 of 5) and DN2A (3 of 5) populations (Figure 3B), whereas in the absence of EphA3, the DN (CD44/CD25) profiles show thymocytes in differentiation stages other than DN1, including DN3 and DN4. Notably, only one of the five $E p h A 3^{+/+}$T-ALLs demonstrated appreciable EPHA3 expression. Together, this demonstrated that deletion of EphA3 reduced-but did not eliminate-the incidence of T-ALL in the NHD13 model. 
A

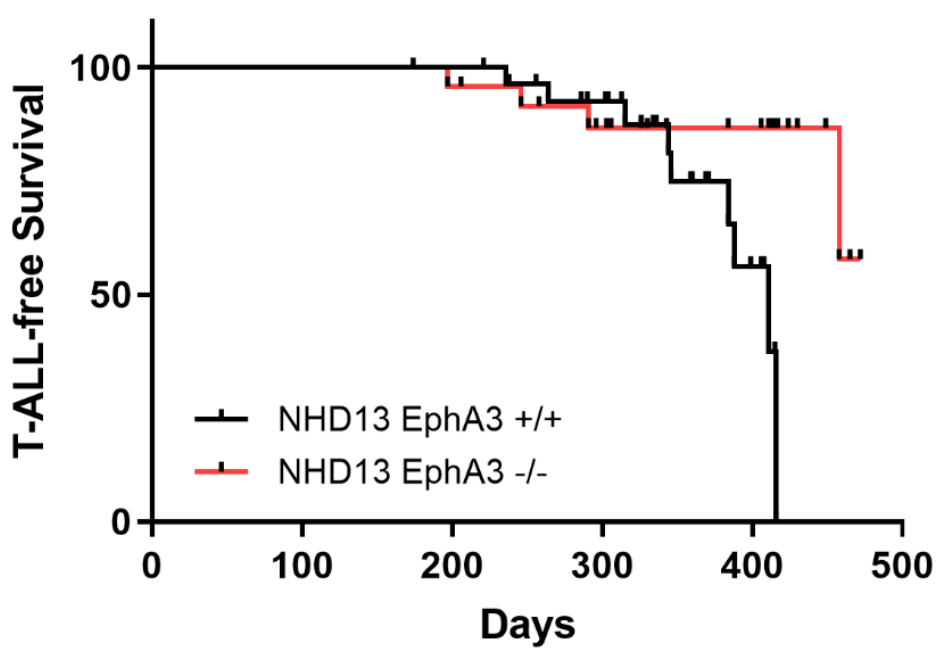

$\mathrm{B}$

NHD13

EphA3 +/+

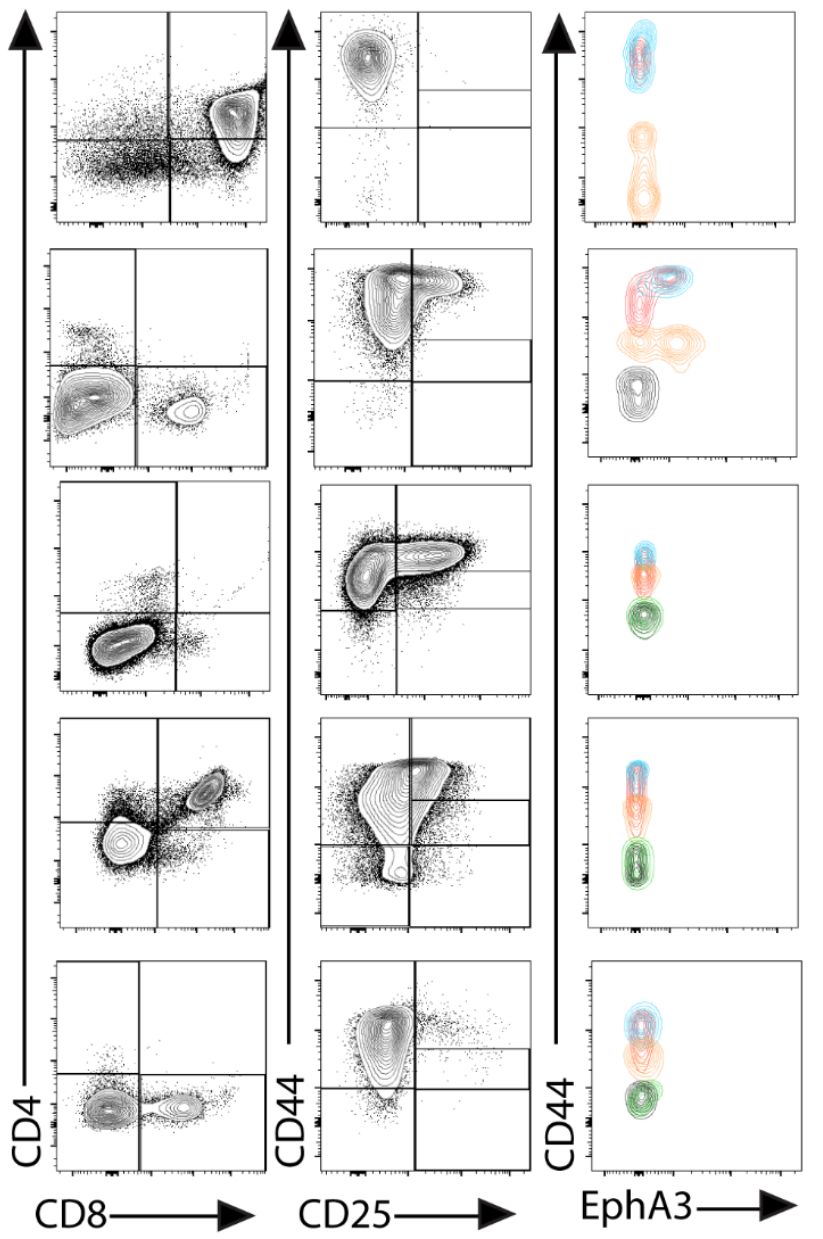

C

NHD13

EphA3 -/-

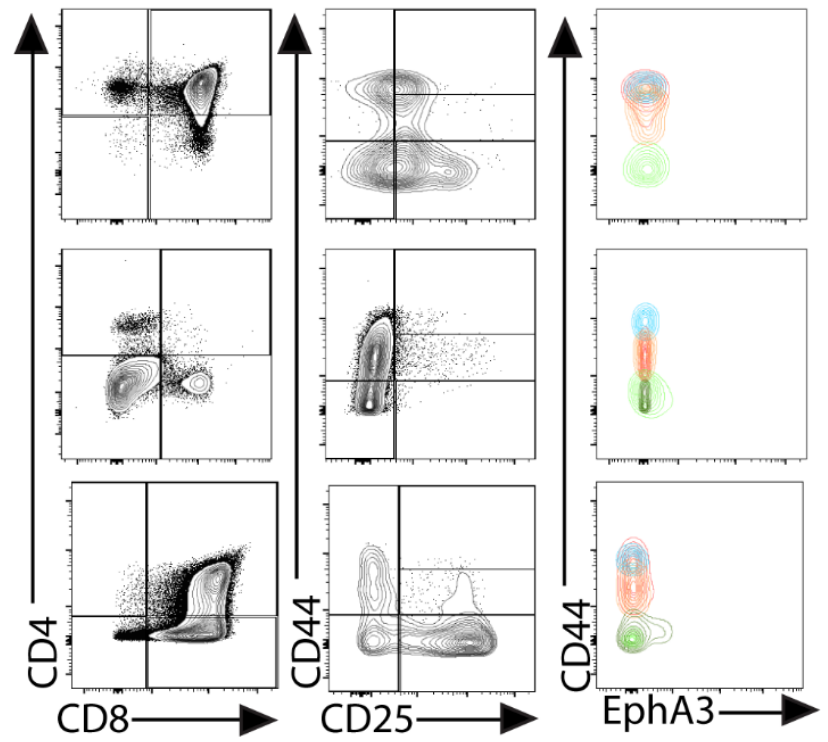

Figure 3. EphA3 deletion reduces T-ALL incidence in NHD13 mice. (A) Kaplan-Meier plot of T-ALL-free survival for each indicated genotype, with deaths due to causes other than T-ALL excluded. (B,C) Representative cell profiles and EPHA3 detection in T-ALL leukaemias of (B) NHD13 EphA3 $3^{+/}$and (C) NHD13 EphA3 ${ }^{-/-}$mice, using CD4/CD8, CD44/CD25, and CD44/EPHA3. The colour of the contour plots matches the colour of the gated DN1-4 populations from Figure 1B. 


\subsection{Sustained Abnormal Expression of Self-Renewal Genes in the Absence of EphA3}

The stem-like transcriptional signature downstream of the NUP98-HOXD13 fusion protein has LMO2-like, Lyl1-dependent, and Lyl1-independent components [6]. To determine any impact of EphA3 deletion on this self-renewal signature, we compared the

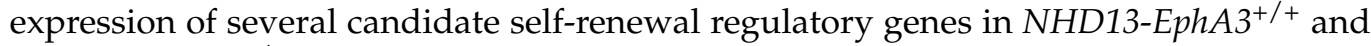
NHD13-EphA3 ${ }^{-/-}$thymocytes, using qRT-PCR. We previously showed overexpression of HoxA genes such as HoxA5, HoxA7, HoxA9, and HoxA10 in NHD13 DN thymocytes [8]. We found no differences in the profiles of overexpression of these genes in whole NHD13 thymus tissue in the presence or absence of EphA3 (Figure 4). Similarly, oncogenes such as Lmo2, Lyl1, Hhex, and Klf2-which are all deregulated in NHD13 DN2 thymocytesshowed no significant changes in expression when comparing $N H D 13-E p h A 3^{+/+}$and NHD13-EphA3 ${ }^{-/-}$DN2 thymocytes (Figure 4). These results suggest that EphA3 exerts influence via an independent mechanism to those previously described in T-ALL mouse models.

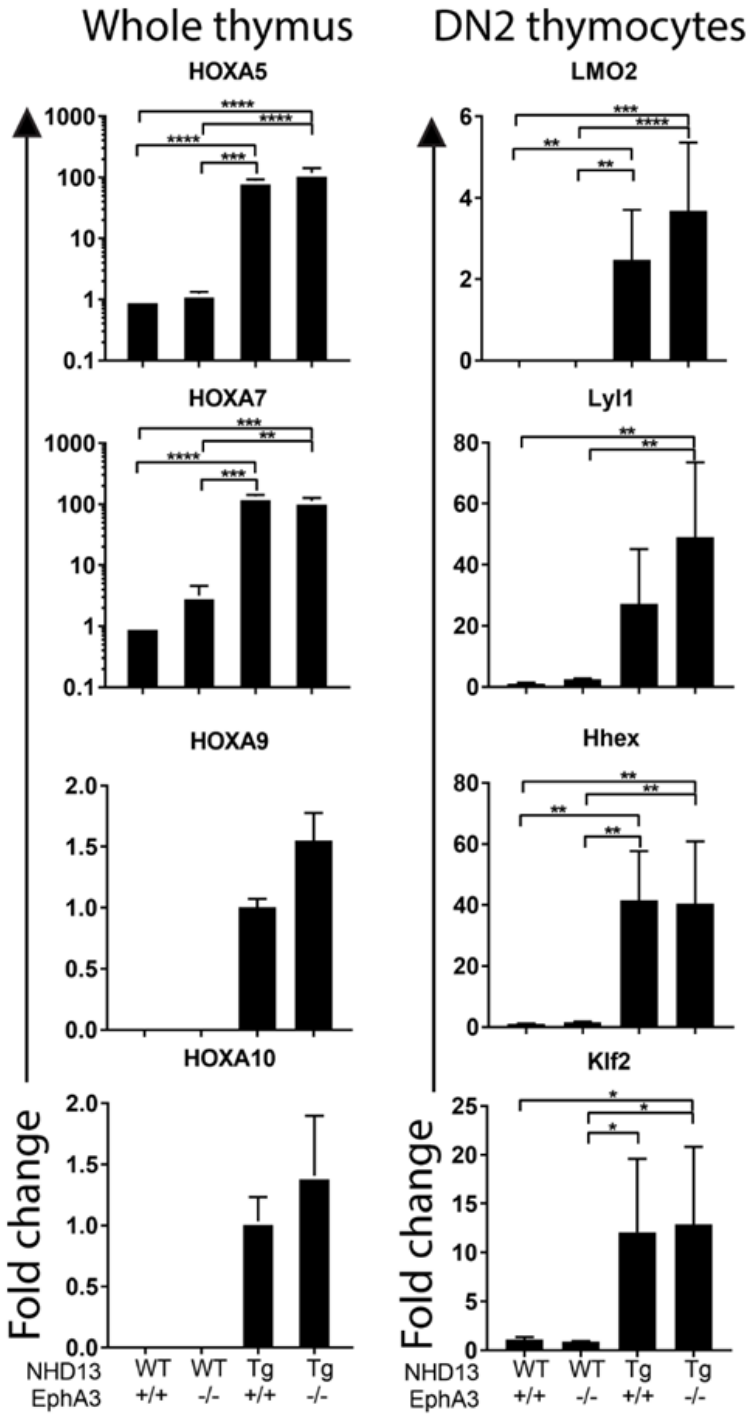

Figure 4. NHD13 abnormal self-renewal gene expression is unaffected by EphA3 deletion. RT-PCR testing was performed using 6-week-old whole thymus (left column) or FACS-sorted DN2 (DN2A and $\mathrm{DN} 2 \mathrm{~B}, \mathrm{CD} 44^{+}, \mathrm{CD} 25^{+}$right column) thymocyte samples for each indicated genotype. The average fold change expression of HoxA5, HoxA7, HoxA9, HoxA10, LMO2, Lyl1, Hhex, and Klf2 genes was as indicated. Bars represent the mean \pm S.E.M of three mice per group. $p$-values were calculated using Student's $t$-test $\left.{ }^{*} p<0.05,{ }^{* *} p<0.005,{ }^{* * *} p<0.0005,{ }^{* * * *} p<0.00005\right)$. 


\subsection{EphA3 Mediates an Interaction between Donor and Recipient Thymocytes}

The NHD13 thymocytes' abnormal ability to self-renew is functionally defined by their capacity to engraft upon transplantation, and to retain this ability indefinitely upon serial transplantation.

To assess the engraftment ability of NHD13 thymocytes in the absence of EphA3, we performed serial transplantation of $N H D 13-E p h A 3^{-/-}$thymocytes into sub-lethally irradiated wild-type mice, and evaluated donor chimerism 4 weeks later (Figure $5 \mathrm{~A}$ ). We found that NHD13-EphA3 ${ }^{-/-}$thymocytes are able to engraft similarly to NHD13-EphA3 ${ }^{+/+}$thymocytes (Figure $5 \mathrm{~B}$ ), with a donor contribution in the DN compartment of $70 \%$ and $65 \%$ in the first and second transplants, respectively (Figure 5C). Strikingly, the NHD13-EphA3 ${ }^{-1-}$ thymocytes failed to engraft upon the third serial transplant, whereas the NHD13-EphA3 $3^{+/+}$ thymocytes engrafted indefinitely (Figure $5 B, C$ ). In parallel, the cellularity of the thymus (Figure 5D) and the proportions of the DN1-4 populations (Figure 5E) were rescued by the third transplant in the NHD13-EphA3 ${ }^{-/-}$recipients, and were similar to the WT$E p h A 3^{+/+}$and WT-EphA3 $3^{-/-}$control recipients. These experiments were performed on three occasions from independent donors, and similar results were seen in each replicate. Therefore, EphA3 is dispensable for primary and secondary engraftment, but essential for serial engraftment.

Furthermore, in the primary transplants that received NHD13-EphA3 ${ }^{-1-}$ thymocytes, the recipient WT thymocytes (CD45.1) exhibited a strikingly different DN cell profile compared to the thymuses transplanted with $N H D 13-E p h A 3^{+/+}$thymocytes (Figure 5B). In the NHD13-E $\mathrm{phA3} 3^{+/+}$primary recipient, there was an accumulation of the recipient thymocytes in the DN1 stage compared to either the WT or EphA3 ${ }^{-/-}$thymuses (Figure 5B). These cells appear to be prevented from differentiating beyond the DN1 stage, despite being genetically wild type. However, despite a similar level of engraftment of donor cells in the NHD13-EphA3 ${ }^{-/-}$recipient, the WT recipient cells (CD45.1) show a relatively normal DN distribution (Figure 5F). This suggests that, upon transplantation of NHD13 thymocytes, $E p h A 3$ is required to prevent normal differentiation of the incoming WT progenitor cells. 

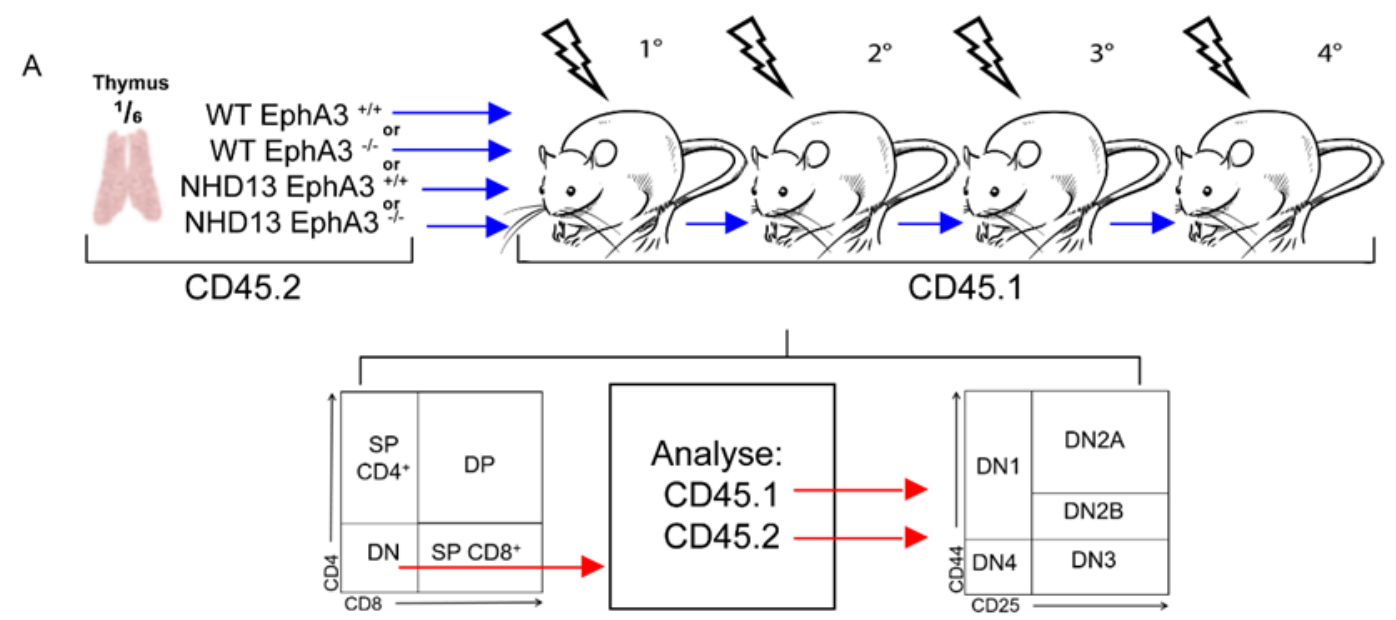

B

CD45.1

CD45.2

\section{E}

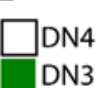

DN3

DN2B

DN2A

DN1
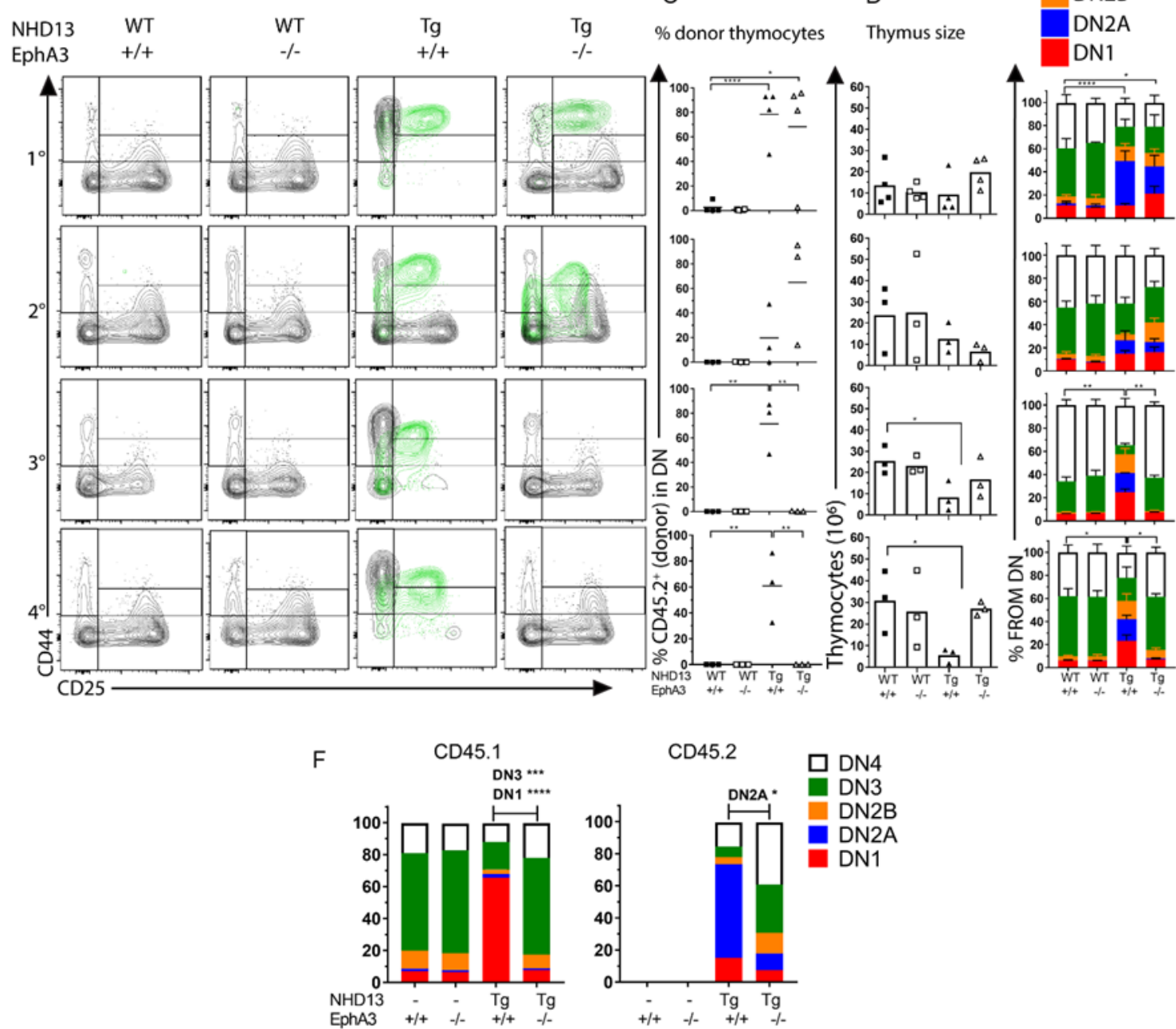

Figure 5. EphA3 prevents the normal differentiation of wild-type thymocytes in recipients, and mediates the long-term selfrenewal capacity of NHD13 thymocytes upon serial transplantation. (A) Schematic representation of experimental design using 6-week-old donor CD45.2 thymuses from WT-EphA3 ${ }^{+/+}$, WT-EphA3 ${ }^{-/-}$, NHD13-EphA3 ${ }^{+/}$, or NHD13-EphA3 ${ }^{-/-}$ mice. CD45.2 thymocytes equivalent to a $1 / 6$ of a thymus were IV injected into sub-lethally irradiated (6.5 Gy) C57BL/6 CD45.1 recipient mice for primary or further serial transplantations. At 4 weeks post-transplantation, engraftment and contribution of donor CD45.2 cells were analysed via flow cytometry. (B) Representative cell profiles of serial transplants 
(e.g., $1^{\circ}$ primary, $2^{\circ}$ secondary, $3^{\circ}$ tertiary, and $4^{\circ}$ quaternary) for each indicated genotype show DN1-4 populations determined by CD44/CD25. Black plots represent recipient CD45.1 cells, while green plots represent engrafted donor CD45.2 cells. (C) Contribution of CD45.2 donor thymocytes of each serial transplant. (D) Thymus cellularity of each serial transplant. (E) Quantitation of DN1-DN4 proportions of each serial transplant. Three biological replicates were performed, and the data represent one biological replicate. (F) Quantitation of DN1-DN4 split by CD45.1 or CD45.2. (C,D) Data represent the mean, points represent 3 individual mice per group, and $p$-values were calculated using Student's $t$-test $\left({ }^{*} p<0.05,{ }^{* *} p<0.005,{ }^{* * *} p<0.0005,{ }^{* * * *} p<0.00005\right)$. (E,F) Bars represent the mean \pm S.E.M, $p$-values were calculated using a two-way ANOVA, and the significance refers to the DN2A populations.

\subsection{NHD13 DN2 Thymocytes Induce Cell Cycle Arrest on WT Cells Independently of EphA3 Expression}

Another characteristic of $\mathrm{NHD13}-\mathrm{EphA3}^{+/+}$thymocytes is their increased quiescence compared to WT cells [6]. This has not yet been assessed in transplant recipients, nor in the context of EphA3. To investigate whether EPHA3 expression modulates the cell division of NHD13 thymocytes and neighbouring wild-type thymocytes, we analysed the cell cycling status of DN2 (DN2A and DN2B) thymocytes in the primary transplant recipients.

We found that, following transplant, donor NHD13-EphA3 ${ }^{+/+}$thymocytes are more quiescent than recipient thymocytes from control WT-EphA3 ${ }^{+/+}$recipient mice (in which no donor cells engraft) (Figure 6). This is similar to what was previously described for NHD13 thymocytes prior to transplantation [6]. However, there were no differences in the cell cycle status in the NHD13-EphA3 - / - cells compared to the NHD13-EphA3 ${ }^{+/+}$cells (Figure 6), indicating that EphA3 deletion does not affect the cell cycle status of NHD13 thymocytes. We also observed that in both NHD13-EphA3 ${ }^{+/+}$and NHD13-EphA3 ${ }^{-/}$transplants, the WT recipient cells (CD45.1) divided at a lower rate compared to the equivalent WT recipient cells (CD45.1) in the thymuses transplanted with WT-EphA3 ${ }^{+/+}$or WT-EphA3 ${ }^{-/-}$ thymocytes (Figure 6). This observation suggests that, independently of EphA3 expression, NHD13 thymocytes hamper the cell division of proximal WT thymocytes. We also analysed the cell cycle status of the DN1, DN3, and DN4 thymocytes (Supplementary Figure S3) and found that, although NHD13 cells generally cycle slower than wild-type cells, the effect of the NHD13 thymocytes on the wild-type recipients only occurs in DN2.

\section{DN2}

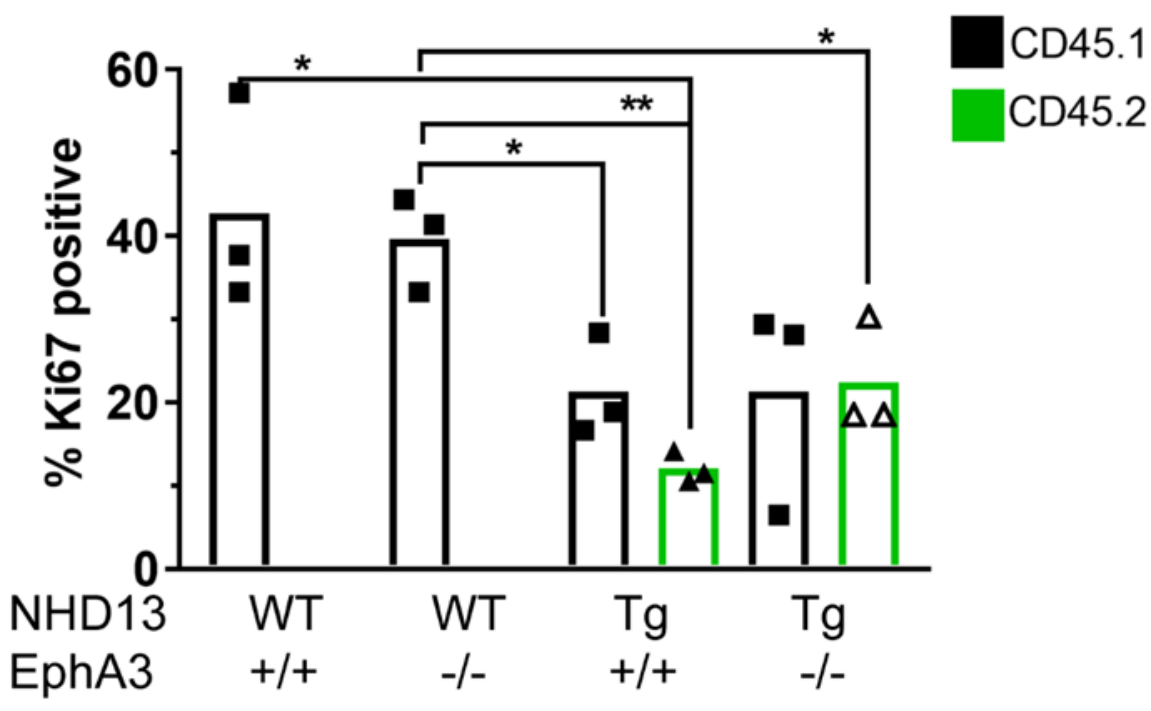

Figure 6. Cell division arrest of WT thymocytes by NHD13 thymocytes. Cell division analysis of DN2 (DN2A and DN2B) thymocytes in the primary transplant recipient. DN2 $\left(\mathrm{CD} 44^{+}, \mathrm{CD} 25^{+}\right)$recipient (CD45.1) or donor (CD45.2) thymocytes were analysed for cell division/quiescent status using Ki67 and DNA (Hoechst) stains. Bars represent the mean, points represent 3 individual mice per group, and $p$-values were calculated using Student's $t$-test $\left({ }^{*} p<0.05,{ }^{* *} p<0.005\right)$. 
Therefore, we conclude that multiple cell-extrinsic effects are perpetrated on wild-type recipient thymocytes by NHD13 thymocytes in the transplant setting. Among these, the block in differentiation of recipient thymocytes is dependent on the expression of EPHA3 by NHD13 thymocytes, and prevention of this effect via the deletion of EphA3 results in a reduction in the incidence of T-ALL in the NHD13 model.

\section{Discussion}

Pre-leukaemic stem cells have previously been characterised on the basis of their ability to self-renew inappropriately, as defined by an engraftment assay. This has been considered a cell-intrinsic ability, granted by the inappropriate expression of stem-like transcription factors. However, the removal of this transplantation ability from NHD13 thymocytes, via the deletion of Lyl1, does not impact on T-ALL incidence [6]. Therefore, there must be another, perhaps redundant, mechanism responsible.

In the present study, we characterise the role of EphA3 in pre-leukaemic thymocytes in the NHD13 mouse model. EPHA3 is typically considered to be undetectable in adult tissues (both mouse and human), and has been described extensively as being overexpressed in a wide variety of haematological malignancies [19,26-28]. In myeloid leukaemias and other cancers, EphA3 has been identified as a regulator of stem cell abilities [20-22,31]. We find that, in the NHD13 mouse model, EphA3 expression in the thymus is restricted to the expanded DN2 compartment. We show that, although EphA3 deletion delays the phenotype, EphA3 is not required for the NHD13 thymic phenotype. NHD13 thymuses have an expanded DN2 compartment, increased DN1 compartment, and reduced overall cellularity. The expanded population displays a marked overexpression of C-KIT, which is important in early T-cell differentiation in the thymus, and which is required for the transplantation ability and radioresistance of Lmo2 transgenic thymocytes. [32-35]. EphA3 deletion reduces each of these, to an extent, at 6 weeks of age, but makes no difference to these outcomes in 12-week-old mice.

In a survival study, however, EphA3 deletion reduced the incidence of T-ALL in NHD13 mice, decreasing the incidence by almost half $\left(30 \% \mathrm{NHD} 13-E \mathrm{phA} 3^{+/+}\right.$compared to $16 \%$ NHD13-EphA3 $3^{-/-}$mice). Much of the difference is seen in older mice, perhaps suggesting that EphA3 is especially important in late-onset T-ALL in this model. We investigated the expression of several genes believed to be involved in the abnormal selfrenewal and leukaemogenicity of these cells, and found that all continued to be abnormally overexpressed in NHD13 thymocytes in the absence of EphA3.

Our transplantation study showed that, although EphA3 is not required for the engraftment capacity of pre-leukaemic NHD13 thymocytes, there is an important difference in the behaviour of the wild-type recipient thymocytes in this setting. When transplanted with NHD13 thymocytes, the recipient animal's own thymocytes are unable to progress beyond DN1, seemingly blocked by the expanded DN2 population of NHD13 donor cells. However, when EphA3 is deleted from the NHD13 donor cells, the recipient thymocytes are able to progress normally through DN2 and DN3, to DN4 and beyond.

Previous studies have demonstrated that continual import of progenitors from the bone marrow into the thymus is essential to maintain cell competition in the thymus-a key process to sustain the normal differentiation and homeostasis of thymocytes. The absence of normal cell competition results in the abnormal self-renewal of WT thymocytes, and is leukaemogenic [36-40]. In the models used in the studies that demonstrated this, the recipient mice were deficient in incoming progenitors, so the incumbent thymocytes were not outcompeted, and could instead remain in the thymus. This long occupancy presumably permits them time to accumulate mutations and become leukaemogenic. In our NHD13 thymocyte transplantation model, following the four-week engraftment period, recipient thymuses contained two populations of cells: NHD13 cells that were transplanted and engrafted in the thymus, and wild-type "progenitor" cells that were newly arrived from the bone marrow. At 4 weeks post-transplantation, incoming WT cells had accumulated in the DN1 stage, as they were prevented from progressing through 
their normal differentiation pathway by the presence of $N H D 13-E p h A 3^{+/+} \mathrm{DN} 2$ cells. This may result in an inefficient cell competition in DN3, with no "young" progenitors coming in to outcompete the incumbent "old" progenitors. When EphA3 is deleted, although transplanted NHD13-EphA3 ${ }^{-/-}$cells still accumulate in the DN2 stage, the incoming WT cells complete their differentiation process normally, which may restore cell competition in DN3. This difference in the progression of incoming thymic progenitors may also explain the differences seen between non-transplanted NHD13-EphA3 $3^{+/+}$and NHD13-EphA3 $3^{-/-}$ thymuses at six weeks of age, but that were absent at 12 weeks of age (Figure 2). The progression of incoming progenitors beyond DN1 in the absence of EphA3 is more normal than in the presence of $E p h A 3$, but because these incoming progenitors are still expressing NHD13, they mostly accumulate in DN2, and predominantly do not progress normally. This is different to the transplant setting, where the incoming progenitors are wild-type recipient cells, and will progress normally if they are able.

Based on the extracellular nature of $E p h A 3$, and the fact that we have shown that DN2 NHD13-EphA3 $3^{+/+}$thymocytes are known to be responsible for the impaired thymocyte turnover, it seems likely that EPHA3 may mediate a cell-cell interaction that stops the incoming WT thymocytes in the DN1 stage, and prevents new progenitors from being imported into the thymus. This "blockade" capacity is independent of the ability of NHD13 thymocytes to accumulate in the DN2 stage, as this accumulation occurs in the absence of $E p h A 3$. This accumulation is likely driven by the maintained self-renewal gene expression signature of the Lyl1 gene.

In the NHD13 mouse model, we propose that the reduction of the cell competition inhibition mechanism via the deletion of EphA3 is insufficient to prevent the development of T-ALL (although it does reduce the incidence). Cell competition is restored by deletion of $E p h A 3$, but the intrinsic self-renewal capacity of the NHD13 thymocytes driven by Lyl1 [6] remains intact. As reported previously, although Lyl1 is required for the transplantability and establishment of a stem-cell-like gene expression program in NHD13 thymocytes, deletion of Lyl1 is also not sufficient to prevent T-ALL [6]. Therefore, we suggest that the development of T-ALL in the NHD13 model is prompted by a complex interplay of cell-intrinsic and cell-extrinsic factors. It is clear that NHD13 thymocytes employ at least two different mechanisms of leukaemogenesis, and that each is sufficient for leukaemia to occur: (1) the expression of the oncogene Lyl1, and (2) the inhibition of cell competition mediated by EPHA3.

Our findings also report insights into new cellular mechanisms by which NHD13 pre-leukaemic stem cells are able to manipulate WT normal cells. We found that both NHD13 and wild-type DN2 cells in NHD13-recipient thymuses divide at a slower rate. This suggests that the presence of the NHD13 cells can inhibit the normal cell division of the wild-type DN2 cells. This effect was independent of EphA3, indicating that there is more than one means of communication between NHD13 and wild-type thymocytes in our transplant model.

\section{Conclusions}

In the present study, the deletion of EphA3 resulted in the restoration of normal cell competition in NHD13 thymuses, and reduced the incidence of T-ALL as a result. This supports earlier work [37] demonstrating that cell competition is a tumour suppressor in the thymus, in a model that was not specifically engineered to disrupt incoming thymocyte progenitors. We have, for the first time, identified a cell competition mechanism in a non-engineered model, and further identified a molecular mediator responsible for the establishment of this mechanism. Given the perceived role of EphA3 in self-renewal in other settings, it is interesting to ponder whether these phenomena might also be due to a contribution of cell competition to self-renewal.

Supplementary Materials: The following are available online at https:/ /www.mdpi.com/article/10 .3390 / cancers13153858/s1, Figure S1: Quantitation of double-negative (DN), double-positive (DP), single-positive CD4+ (SP4), and single-positive CD8+ (SP8) populations; Figure S2. EphA3 deletion 
does not impact the incidence of AML in the NHD13 mice; Figure S3. EphA3 deletion does not impact the cell cycle of wild type recipient cells in DN1, DN3 or DN4.

Author Contributions: Conceptualization, A.C.P.Z. and C.I.S.; investigation, A.C.P.Z., H.R., J.E.L., C.K.N., S.H., R.W., and C.I.S.; formal analysis, A.C.P.Z., H.R., J.E.L., C.K.N., and C.I.S.; resources, A.M.S. and A.W.B.; writing-original draft preparation, A.C.P.Z.; writing-review and editing, A.C.P.Z. and C.I.S.; funding acquisition, A.C.P.Z. and C.I.S. All authors have read and agreed to the published version of the manuscript.

Funding: This research was funded by NHMRC grant number 1099381, and Advance Queensland, Women's Academic Fund.

Institutional Review Board Statement: The study was approved by the Animal Ethics Committee of the University of Queensland (169/16, approved 17 May 2016; 013/17, approved 29 March 2017).

Acknowledgments: We thank the UQ Biological Resources facility at the Translational Research Institute, Brisbane, Australia, and the Flow Cytometry facility at the Translational Research Institute, Brisbane, Australia, for housing our experiments. We thank J. Daniel Bautista for providing the mouse illustrations.

Conflicts of Interest: The authors declare no conflict of interest.

\section{References}

1. Zhang, J.; Ding, L.; Holmfeldt, L.; Wu, G.; Heatley, S.L.; Payne-Turner, D.; Easton, J.; Chen, X.; Wang, J.; Rusch, M.; et al. The genetic basis of early T-cell precursor acute lymphoblastic leukaemia. Nature 2012, 481, 157-163. [CrossRef]

2. Ferrando, A.A.; Neuberg, D.S.; Staunton, J.; Loh, M.L.; Huard, C.; Raimondi, S.C.; Behm, F.G.; Pui, C.H.; Downing, J.R.; Gilliland, D.G.; et al. Gene expression signatures define novel oncogenic pathways in T cell acute lymphoblastic leukemia. Cancer Cell 2002, 1, 75-87. [CrossRef]

3. Van Vlierberghe, P.; Pieters, R.; Beverloo, H.B.; Meijerink, J.P. Molecular-genetic insights in paediatric T-cell acute lymphoblastic leukaemia. Br. J. Haematol. 2008, 143, 153-168. [CrossRef]

4. Girardi, T.; Vicente, C.; Cools, J.; De Keersmaecker, K. The genetics and molecular biology of T-ALL. Blood 2017, 129, 1113-1123. [CrossRef]

5. Eguchi-Ishimae, M.; Eguchi, M.; Kempski, H.; Greaves, M. NOTCH1 mutation can be an early, prenatal genetic event in T-ALL. Blood 2008, 111, 376-378. [CrossRef] [PubMed]

6. Shields, B.J.; Slape, C.I.; Vo, N.; Jackson, J.T.; Pliego-Zamora, A.; Ranasinghe, H.; Shi, W.; Curtis, D.J.; McCormack, M.P. The NUP98-HOXD13 fusion oncogene induces thymocyte self-renewal via Lmo2/Lyl1. Leukemia 2019, 33, 1868-1880. [CrossRef]

7. McCormack, M.P.; Young, L.F.; Vasudevan, S.; de Graaf, C.A.; Codrington, R.; Rabbitts, T.H.; Jane, S.M.; Curtis, D.J. The Lmo2 oncogene initiates leukemia in mice by inducing thymocyte self-renewal. Science 2010, 327, 879-883. [CrossRef] [PubMed]

8. Choi, C.W.; Chung, Y.J.; Slape, C.; Aplan, P.D. A NUP98-HOXD13 fusion gene impairs differentiation of B and T lymphocytes and leads to expansion of thymocytes with partial TCRB gene rearrangement. J. Immunol. 2009, 183, 6227-6235. [CrossRef] [PubMed]

9. Lin, Y.W.; Slape, C.; Zhang, Z.; Aplan, P.D. NUP98-HOXD13 transgenic mice develop a highly penetrant, severe myelodysplastic syndrome that progresses to acute leukemia. Blood 2005, 106, 287-295. [CrossRef] [PubMed]

10. Kania, A.; Klein, R. Mechanisms of ephrin-Eph signalling in development, physiology and disease. Nat. Rev. Mol. Cell Biol. 2016, 17, 240-256. [CrossRef]

11. Holder, N.; Klein, R. Eph receptors and ephrins: Effectors of morphogenesis. Development 1999, 126, 2033-2044. [CrossRef] [PubMed]

12. Anderton, M.; van der Meulen, E.; Blumenthal, M.J.; Schafer, G. The role of the Eph receptor family in tumorigenesis. Cancers 2021, 13, 206. [CrossRef]

13. Janes, P.W.; Vail, M.E.; Ernst, M.; Scott, A.M. Eph receptors in the immunosuppressive tumor environment. Cancer Res. 2021, 81, 801-805. [CrossRef] [PubMed]

14. Brantley-Sieders, D.M. Clinical relevance of Ephs and ephrins in cancer: Lessons from breast, colorectal, and lung cancer profiling. Semin. Cell Dev. Biol. 2012, 23, 102-108. [CrossRef] [PubMed]

15. Hill, W.; Hogan, C. Normal epithelial cells trigger EphA2-dependent RasV12 cell repulsion at the single cell level. Small GTPases 2019, 10, 305-310. [CrossRef] [PubMed]

16. Boyd, A.W.; Ward, L.D.; Wicks, I.P.; Simpson, R.J.; Salvaris, E.; Wilks, A.; Welch, K.; Loudovaris, M.; Rockman, S.; Busmanis, I. Isolation and characterization of a novel receptor-type protein tyrosine kinase (hek) from a human pre-B cell line. J. Biol. Chem. 1992, 267, 3262-3267. [CrossRef]

17. Dottori, M.; Down, M.; Huttmann, A.; Fitzpatrick, D.R.; Boyd, A.W. Cloning and characterization of EphA3 (Hek) gene promoter: DNA methylation regulates expression in hematopoietic tumor cells. Blood 1999, 94, 2477-2486. [CrossRef]

18. Guan, M.; Liu, L.; Zhao, X.; Wu, Q.; Yu, B.; Shao, Y.; Yang, H.; Fu, X.; Wan, J.; Zhang, W. Copy number variations of EphA3 are associated with multiple types of hematologic malignancies. Clin. Lymphoma Myeloma Leuk. 2011, 11, 50-53. [CrossRef] 
19. Tomasevic, N.; Luehrsen, K.; Baer, M.; Palath, V.; Martinez, D.; Williams, J.; Yi, C.; Sujatha-Bhaskar, S.; Lanke, R.; Leung, J.; et al. A high affinity recombinant antibody to the human EphA3 receptor with enhanced ADCC activity. Growth Factors 2014, 32, 223-235. [CrossRef]

20. Ashton, J.M.; Balys, M.; Neering, S.J.; Hassane, D.C.; Cowley, G.; Root, D.E.; Miller, P.G.; Ebert, B.L.; McMurray, H.R.; Land, H.; et al. Gene sets identified with oncogene cooperativity analysis regulate in vivo growth and survival of leukemia stem cells. Cell Stem Cell 2012, 11, 359-372. [CrossRef]

21. Day, B.W.; Stringer, B.W.; Al-Ejeh, F.; Ting, M.J.; Wilson, J.; Ensbey, K.S.; Jamieson, P.R.; Bruce, Z.C.; Lim, Y.C.; Offenhauser, C.; et al. EphA3 maintains tumorigenicity and is a therapeutic target in glioblastoma multiforme. Cancer Cell 2013, 23, 238-248. [CrossRef]

22. Chen, J.; Song, W.; Amato, K. Eph receptor tyrosine kinases in cancer stem cells. Cytokine Growth Factor Rev. 2015, 26, 1-6. [CrossRef]

23. Janes, P.W.; Vail, M.E.; Gan, H.K.; Scott, A.M. Antibody Targeting of Eph Receptors in Cancer. Pharmaceuticals 2020, 13, 88. [CrossRef] [PubMed]

24. Gan, H.; Cher, L.; Inglis, P.; Lwin, Z.; Lau, E.; Ackermann, U.; Coombs, N.; Remen, K.; Guo, N.; Lee, S.T.; et al. Preliminary Findings of a Phase I Safety and Bioimaging Trial of Kb004 (Ifabotuzumab) in Patients with Glioblastoma. Neuro Oncol. 2019, 21, 6. [CrossRef]

25. Offenhauser, C.; Al-Ejeh, F.; Puttick, S.; Ensbey, K.S.; Bruce, Z.C.; Jamieson, P.R.; Smith, F.M.; Stringer, B.W.; Carrington, B.; Fuchs, A.V.; et al. EphA3 Pay-Loaded Antibody Therapeutics for the Treatment of Glioblastoma. Cancers 2018, 10, 519. [CrossRef] [PubMed]

26. Caivano, A.; La Rocca, F.; Laurenzana, I.; Annese, T.; Tamma, R.; Famigliari, U.; Simeon, V.; Trino, S.; De Luca, L.; Villani, O.; et al. Epha3 acts as proangiogenic factor in multiple myeloma. Oncotarget 2017, 8, 34298-34309. [CrossRef]

27. Charmsaz, S.; Al-Ejeh, F.; Yeadon, T.M.; Miller, K.J.; Smith, F.M.; Stringer, B.W.; Moore, A.S.; Lee, F.T.; Cooper, L.T.; Stylianou, C.; et al. EphA3 as a target for antibody immunotherapy in acute lymphoblastic leukemia. Leukemia 2017, 31, 1779-1787. [CrossRef]

28. Swords, R.T.; Greenberg, P.L.; Wei, A.H.; Durrant, S.; Advani, A.S.; Hertzberg, M.S.; Jonas, B.A.; Lewis, I.D.; Rivera, G.; Gratzinger, D.; et al. KB004, a first in class monoclonal antibody targeting the receptor kinase EphA3, in patients with advanced hematologic malignancies: Results from a phase 1 study. Leuk. Res. 2016, 50, 123-131. [CrossRef] [PubMed]

29. Vaidya, A.; Pniak, A.; Lemke, G.; Brown, A. EphA3 null mutants do not demonstrate motor axon guidance defects. Mol. Cell Biol. 2003, 23, 8092-8098. [CrossRef]

30. Barbier, V.; Nowlan, B.; Levesque, J.P.; Winkler, I.G. Flow cytometry analysis of cell cycling and proliferation in mouse hematopoietic stem and progenitor cells. Methods Mol. Biol. 2012, 844, 31-43. [CrossRef]

31. Janes, P.W.; Slape, C.I.; Farnsworth, R.H.; Atapattu, L.; Scott, A.M.; Vail, M.E. EphA3 biology and cancer. Growth Factors 2014, 32, 176-189. [CrossRef]

32. Buono, M.; Facchini, R.; Matsuoka, S.; Thongjuea, S.; Waithe, D.; Luis, T.C.; Giustacchini, A.; Besmer, P.; Mead, A.J.; Jacobsen, S.E.; et al. A dynamic niche provides Kit ligand in a stage-specific manner to the earliest thymocyte progenitors. Nat. Cell Biol. 2016, 18, 157-167. [CrossRef]

33. Rodewald, H.R.; Kretzschmar, K.; Swat, W.; Takeda, S. Intrathymically expressed c-kit ligand (stem cell factor) is a major factor driving expansion of very immature thymocytes in vivo. Immunity 1995, 3, 313-319. [CrossRef]

34. Smith, L.M.; Walsh, P.T.; Rudiger, T.; Cotter, T.G.; Mc Carthy, T.V.; Marx, A.; O'Connor, R. EphA3 is induced by CD28 and IGF-1 and regulates cell adhesion. Exp. Cell Res. 2004, 292, 295-303. [CrossRef] [PubMed]

35. Shields, B.J.; Alserihi, R.; Nasa, C.; Bogue, C.; Alexander, W.S.; McCormack, M.P. Hhex regulates Kit to promote radioresistance of self-renewing thymocytes in Lmo2-transgenic mice. Leukemia 2015, 29, 927-938. [CrossRef] [PubMed]

36. Ballesteros-Arias, L.; Silva, J.G.; Paiva, R.A.; Carbonetto, B.; Faisca, P.; Martins, V.C. T Cell Acute Lymphoblastic Leukemia as a Consequence of Thymus Autonomy. J. Immunol. 2019, 202, 1137-1144. [CrossRef]

37. Martins, V.C.; Busch, K.; Juraeva, D.; Blum, C.; Ludwig, C.; Rasche, V.; Lasitschka, F.; Mastitsky, S.E.; Brors, B.; Hielscher, T.; et al. Cell competition is a tumour suppressor mechanism in the thymus. Nature 2014, 509, 465-470. [CrossRef] [PubMed]

38. Martins, V.C.; Ruggiero, E.; Schlenner, S.M.; Madan, V.; Schmidt, M.; Fink, P.J.; von Kalle, C.; Rodewald, H.R. Thymus-autonomous T cell development in the absence of progenitor import. J. Exp. Med. 2012, 209, 1409-1417. [CrossRef]

39. Peaudecerf, L.; Lemos, S.; Galgano, A.; Krenn, G.; Vasseur, F.; Di Santo, J.P.; Ezine, S.; Rocha, B. Thymocytes may persist and differentiate without any input from bone marrow progenitors. J. Exp. Med. 2012, 209, 1401-1408. [CrossRef]

40. Brannan, J.M.; Dong, W.; Prudkin, L.; Behrens, C.; Lotan, R.; Bekele, B.N.; Wistuba, I.; Johnson, F.M. Expression of the receptor tyrosine kinase EphA2 is increased in smokers and predicts poor survival in non-small cell lung cancer. Clin. Cancer Res. 2009, 15, 4423-4430. [CrossRef] 